\title{
Se equivocó el masoreta ¿se equivocaba?
}

Emilia Fernández Tejero*

ILC - CSIC, Madrid

Este artículo, de carácter didáctico, no está destinado a los estudiosos de la Masora, sino a investigadores de áreas cercanas. Las ediciones de manuscritos y los estudios publicados en los últimos años son instrumentos de gran utilidad para quienes deseen adentrarse en un campo de investigación con repercusión en otras áreas tales como la historia del texto bíblico hebreo, su exégesis o los inicios de la gramática. Se analizan tres cuestiones: distinta formulación para una misma noticia, coherencia entre un texto y su masora y posibles discrepancias entre las fuentes.

Palabras Clave: Biblia; Masora; Texto bíblico hebreo.

The Masorete Was Wrong: Was He Wrong?.-This article has a didactic purpose; it is not aimed at scholars of the Masora but rather at researchers in closely associated areas. The editions of Hebrew Biblical manuscripts and critical studies that have been published recently are particularly useful tools for those who wish to delve into other areas of research such as the history of the Hebrew Biblical text, its exegesis or the origins of grammar. Here, the author concentrates on the analysis of three issues: variant formulations of a same information; coherence between a text and its Masorah, and the possible discrepancies among sources.

KeYwords: Bible; Masorah; Hebrew Biblical Text.

En los últimos años se han publicado una serie de trabajos masoréticos que están poniendo al alcance de los investigadores nuevas fuentes que les permitirán acercarse con mayor facilidad a este fascinante campo de trabajo.

Una de las aportaciones más significativas está siendo la publicación de la Biblia Hebraica Quinta ${ }^{1}$. El hecho de editar la masora completa del manuscrito B19a de Leningrado (L), tanto la masora parva (MP) como la masora magna (MM) y dedicar sendos apartados a traducirlas y comentarlas es una clara señal de que, por fin, se ha dado a la masora el puesto que le corresponde en la edición de textos hebreos bíblicos.

\footnotetext{
"emilia.fernandez@cchs.csic.es
}

${ }^{1}$ Biblia Hebraica Quinta. General Introduction and Megillot (Stuttgart 2004); se han publicado también los volúmenes correspondientes a Ezra and Nehemia (2006), Deuteronomy y Proverbs (2008). 
También está siendo relevante la edición de las Mikraot Gedolot 'Haketer' ${ }^{2}$; aunque en una primera fase de estudio su utilización no esté al alcance de los principiantes, en poco tiempo podrán valorar la edición de las masoras del códice de Alepo y las informaciones complementarias que componen el aparato denominado «Fuente de la Masora» ('En Ha-Masorah).

Se han publicado también o están a punto de publicarse obras de introducción a tales estudios, manuales de carácter eminentemente práctico ${ }^{3}$, que ayudarán enormemente a quienes se dispongan a iniciarse en ellos, sea cual fuere su edad.

Bien es verdad que en este campo, como en otros muchos, es difícil ser autodidacta, pero siempre se podrá recurrir a algún experto que, con seguridad, solucionará las dudas y animará a quienes comiencen a seguir una senda nueva.

Guiada por un propósito didáctico, tengo la intención de publicar esporádicamente algunas notas breves que no van destinadas a masoretas, sino a colegas de áreas cercanas interesados en la Masora, con el propósito de aclararles aspectos que, a primera vista, pudieran parecer problemáticos pero que, casi siempre, tienen solución. Y es que, por muy bien que se utilicen las fuentes y recursos referentes a, o publicados sobre, la Masora, resulta difícil, en muchas ocasiones, resolver problemas que sólo pueden solucionarse a base del conocimiento que proporciona una larga experiencia ${ }^{4}$.

Como primer paso, sugiero la lectura del artículo de J. A. Sanders, «Text and Canon: Concepts and Method» ${ }^{5}$. No es un trabajo monográfico sobre la Masora, pero sí una interesante y personalísima descripción de su valoración sobre la labor de los masoretas. Por ejemplo, cuenta cómo en una clase que es-

${ }^{2}$ Editadas por M. CoHEn en la Universidad de Bar-Ilan (Ramat-Gan). Con rigurosa periodicidad, han aparecido entre los años 1992 a 2007 los vols. correpondientes a Josué-Jueces, 1-2 Samuel, 1-2 Reyes, 2 vols. de Génesis, Ezequiel, 2 vols. de Salmos, Isaías y el segundo de Éxodo.

${ }^{3}$ P. H. Kelley, D. S. Mynatt, T. G. Crawford, Masorah of Biblia Hebraica Stuttgartensia/ Introduction and annotated glossary (Grand Rapids, Michigan - Cambridge 1998); F. EDson de Faria, Manual da Bíblia Hebraica: introduçao ao Texto Massorético (2 ed. Sao Paulo 2005); E. Martín Contreras y G. Seijas de los Ríos Zarzosa, La transmisión de la tradición. La masora de la Biblia hebrea (en prensa). Naturalmente, no deben olvidarse en esos primeros pasos los estudios clásicos de I. YeIvin, Introduction to the Tiberian Masorah. Translated and Edited by E. J. Revell (Missoula, Montana 1980) y de A. Dotan, «Masorah», EJ 13 (Detroit, etc. 2007, 2a ed.) cols. 603-656.

${ }^{4}$ Cf. mi reseña a P. H. Kelley, D. S. Mynatt, T. G. Crawford, The Masorah of Biblia Hebraica Stuttgartensia, JSJ XXX (1999) págs. 350-352.

5 J. A. SAnders, «Text and Canon: Concepts and Method», JBL 98 (1979) págs. 5-29: 18 y especialmente 26-29. 
taba impartiendo sobre el Deutero-Isaías, casi como si se hubiera tratado de una revelación, gracias a la nota de MP $\lambda$ (= 3 pasajes) que acompaña a עם en Is 43,21 , descubrió que Isaías 43,16-21 era «a beautiful contemporizing midrash done by the prophet of the exile on the great Song of the Sea». El epígrafe IX parece una llamada a los biblistas que tengan algún gramo de locura para dedicarse a estos estudios.

Me gustaría que los masoretas que se encuentren hoy en día en una situación tal de conocimiento, experiencia y locura se animaran a participar en este proyecto didáctico. Creo que sería conveniente publicar de vez en cuando algunas páginas sobre un fenómeno concreto que haya resultado problemático en sus clases o en sus cursos.

$\mathrm{Y}$ es que no basta con estudiar y aplicar técnicas determinadas. Hay que identificarse con la mentalidad de los masoretas, con su forma de trabajar, con sus propósitos. Mi teoría no responde sólo a la aplicación del principio de crítica textual que defiende el texto difficilior. Hay algo más: debemos abordar el texto con el afecto con el que lo hicieron los masoretas, para cercarlo y protegerlo, como su refugio y defensa, para salvaguardar unos libros que sustentaban su religión, su ley y su vida. Sin olvidar, por el atractivo que supone, el sentido lúdico que tienen estos estudios ${ }^{6}$.

El punto de partida básico del masoreta moderno al editar textos y al estudiarlos, es que, antes de decir que una masora es errónea, hay que agotar todas las posibilidades de compresión de la noticia ${ }^{7}$; intentar, como decía, introducirse en la mente del masoreta y preguntarse si hay alguna razón para que haya presentado una información de manera distinta a la que aparece en otros manuscritos o en las fuentes clásicas de consulta ${ }^{8}$.

Por otro lado, tampoco podemos instalarnos en el extremo opuesto e intentar justificar al máximo lo que carece de justificación. Si un manuscrito tan valioso científicamente como B19a (L), objeto de diversas y cada vez más depuradas

${ }^{6}$ E. FernÁndez Tejero, «El espíritu burlón de los masoretas», Sef 63 (2003) págs. 33-42.

${ }^{7}$ Cf. F. Díaz Esteban, «Los supuestos errores de la Masora», Sef 26 (1966) págs. 3-11.

${ }^{8}$ Ch. D. Ginsburg, The Massorah Compiled from Manuscripts. With an Analytical Table of Contents and List of Identified Sources and Paralles by A. Dotan (New York 1975) 4 vols [lo cito por vol. pág. §]; S. FrensdorfF, Die Massorah Magna. Prolegomenon by G. E. WeIL (New York 1968); Idem, Das Buch Ochla W'Ochla (Hannover 1864); F. Díaz Esteban, Sefer 'Oklah We-'Oklah (Madrid 1975); B. OGNIBENI, La seconda parte del sefer 'oklah we-'oklah (Madrid-Fribourg 1995); G. E. WEIL, Massorah Gedolah iuxta codicem Leningradensem B19a (Romae 1971) [lo cito por el número de lista]. Facilita la consulta de Das Buch Ochlah W'Ochla de S. Frensdorff el trabajo de B. OGNIBENI, Index biblique à la «Ochlah w'ochlah», Quaderni di Henoch 5 (Torino 1987). 
ediciones, tiene un número importante de masoras que van en contra de su propio texto ${ }^{9}$, no es de extrañar que manuscritos posteriores ofrezcan también contradicciones internas e incluso errores.

Estoy totalmente de acuerdo con las palabras de A. Schenker, citadas por C. McCarthy:

As a body can be said to be naked without its clothes, so the Masoretic text of a given manuscript of the Hebrew Bible is incomplete when presented without its own particular Masora,

y con su propia aseveración final:

... one should insist that one must not try to put on one manuscript the clothes that properly belong to another ${ }^{10}$.

Pero para otros propósitos, como el de este artículo, la comparación de las masoras de diferentes manuscritos es válida porque nos permite analizar, entre otras muchas cosas, la igualdad o diferencia de las fuentes utilizadas, las concordancias o discrepancias entre masoras y textos o las tradiciones que pudieron seguir.

En este artículo utilizo el texto y las masoras de los códices L -en la edición BHS ${ }^{11}$, hasta ahora la comúnmente empleada- y el texto y las masoras del códice M1, que están siendo publicadas por el grupo de investigación de «Filología y crítica textual bíblicas» del ILC del CSIC ${ }^{12}$.

${ }^{9}$ Sólo en el Pentateuco, 297. Cf. D. S. Mүnatt, The sub loco notes in the Torah of Biblia Hebraica Stuttgartensia (Louisville, Kentucky 1994).

${ }^{10}$ C. McCarthy, «A Comparative Study of the Masora Magna and Parva of the Book of Deuteronomy as attested in the Leningrad and Madrid M1 Manuscripts», en Sôfer Mahîr. Essays in Honour of Adrian Schenker Offered by the Editors of Biblia Hebraica Quinta. Edited by Y. A. P. Goldman, A. Van der Kools and R. D. Weis (Boston 2006) págs. 177-191: 177, 191.

${ }^{11}$ Biblia Hebraica Stuttugartensia... Masoram elaboravit G. E. WeIL (3a ed. Stuttgart 1987). Es cierto que G. E. WeIL, Massorah Gedolah iuxta codicem leningradensem B 19 a (Romae 1971), elaboravit la masora del manuscrito (cf. sus Prolegomena a la BHS, págs. XXX-XXXVI) pero, pese a los problemas metodológicos que puedan criticársele, su obra es de gran utilidad para una primera toma de contacto en la interpretación de las noticias masoréticas. Sin embargo, en ocasiones, hay que recurrir, y he recurrido, a la edición facsímil del códice para saber la información exacta que presenta el manuscrito. The Leningrad Codex. A Facsimile Edition. General Editor D. N. Freedman (Michigan - Cambridge - Leiden - New York - Köln 1998).

${ }^{12}$ Publicadas todas en la colección «Textos y Estudios» del CSIC. En orden cronológico: M. J. de Azcárraga Servert, Las masoras del libro de Números. Códice M1 de la Universidad Complutense de Madrid (Madrid 2001); M. T. Ortega Monasterio, Las masoras del libro 
Vamos a analizar ejemplos ilustrativos de tres fenómenos.

\section{Una misma información con formulación diferente}

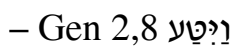

M1: $\quad$ MP: $\uparrow$ (4 pasajes)

MM: ..... דוסימנהון (4 pasajes y sus sîmanîm ${ }^{13} \ldots$ )

BHS: MP ג (3 pasajes)

Tanto la MP como la MM de M1 anotan $\dot{\tau}$; BHS carece de MM y anota $\dot{\lambda}$ en la MP; en la MM de M1 se desarrollan los cuatro sîmanîm de los pasajes correspondientes: Gen 2,8; 9,20;21,33 y Dan 11,45, pero antes del de Daniel se nos advierte que ese caso lleva rafeh, es decir, de que el I va vocalizado con sewa' y no con patah como en los tres primeros. En Ginsburg II pág. 279 § 214 la explicación está clara: Es decir, nos encontramos ante dos informaciones aparentemente distintas, aunque ambas son correctas.

\section{- אל יהודו - Gen 38,22 -}

M1: $\quad$ MP (5 pasajes y sus simanim están escritos)

MM ....în (5 pasajes y sus sîmanîm...)

BHS: $\quad$ MP i (6 pasajes)

MM .... (6 pasajes y sus sîmanîm...)

En la MM de M1 se dan los sîmanîm de Gen 38,22; Ier 35,17; 2 Par 24,23; Neh 2,5.7; en la de L (Weil 285) y en Ginsburg I pág. 67 §59 se dan los cinco casos recogidos por M1 y además el de Ier 30,4 cuyo texto es ואל יהודה, no exactamente el del lema.

\section{- Gen 34,31 אחותנו}

M1: $\quad$ ג ذ ח חס וא מל (3 pasajes, 2 con grafía defectiva y 1 con grafía plena)

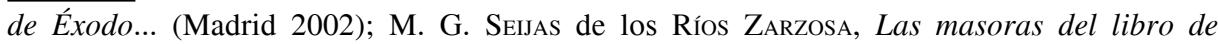
Deuteronomio... (Madrid 2002); M. J. de AzCÁrraga Servert, Las masoras del libro de Levítico... (Madrid 2004); E. Martín Contreras, Apéndices masoréticos... (Madrid 2004); E. Fernández TeJero, Las masoras del libro de Génesis... (Madrid 2004); EAD, Las masoras del libro de Josué... (Madrid 2009).

${ }^{13}$ Plural de sîman. Palabra o palabras clave para identificar los pasajes bíblicos en los que aparece el lema objeto de la información. 
MM (3 pasajes, 2 con grafía defectiva y 1 con grafía plena y sus sîmanîm...)

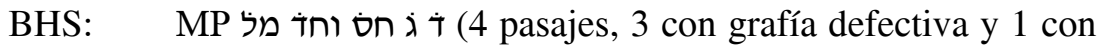
grafía plena)

MM .... ד ל חס וחד מל וסמנחון (4 pasajes, 3 con grafía defectiva y 1 con grafía plena)

Los pasajes enumerados en la MM de M1 son: Gen 24,60; 34,14 y 34,31, con indicación de que el último caso es el de grafía plena. En BHS (Weil 251), se ha incluido entre los casos de grafía defectiva el pasaje de Cant 8,8, donde aparece la palabra לאחותנו que no es exactamente la del lema.

Hay que decir, sin embargo, que el hecho de incluir en el cómputo de las palabras sobre las que se informa otras de la misma raíz, aunque no sean exactamente iguales al lema, no es un fenómeno raro. Pero para indicar el procedimiento el masoreta suele añadir בלשי, en la lî̌sana (= en esa raíz, la misma palabra con o sin partículas, distintas formas verbales, etc.) fórmula que amplía los campos morfológicos y semánticos del lema.

Siguiendo esta idea, también podrían justificarse algunos aparentes errores debidos a informaciones incompletas.

\section{- הערקי... הסיני :Gen 10,17}

M1: en la MP de ambas palabras encontramos la información ל, es decir, que son casos únicos, hápax. Sin embargo, ambas aparecen también en el pasaje paralelo, 1 Par 1,15, donde no hay masoras en M1. Pero el posible error parece demasiado grave, especialmente por tratarse de dos palabras en un mismo y breve versículo que tiene, además, un pasaje paralelo. Este hecho no podía desconocerlo un buen masoreta. Siempre dispuesta a ponerme de su parte, me inclino a pensar que, aunque lo correcto hubiera sido añadir ' בספ (= en el libro), dada la evidencia del caso no lo consideró necesario. En BHS encontramos en ambas palabras la anotación ¿ (2 pasajes).

Y es que no se puede pedir a los masoretas las precisiones metodológicas que se exigen en la actualidad. Ellos conocían, y conocían muy bien -al menos en la época de los masoretas «clásicos»- el texto con el que estaban trabajando y al que añadían sus notas. Esa pericia se perdió más tarde, hasta el punto de que la masora pasó a ser más que un cerco al texto bíblico un ornamento embellecedor, carente, incluso, de coherencia. Pero no es ése el caso de los manuscritos que estamos analizando. 
Tampoco hay que aceptar como verdades absolutas las informaciones contenidas en las fuentes clásicas, sin comprobar antes si el manuscrito con el que trabajamos tiene coherencia interna.

\section{Coherencia entre texto y masoras}

- Gen 25,6 הפילגישם

M1: MP

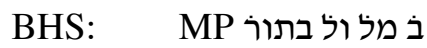

L:

El texto de L es doblemente pleno, הפּינפלגשִים, y por eso Weil ha modificado parcialmente la MP del manuscrito y añadido en nota, «Mp sub loco» ${ }^{14}$; y es que hay otro caso de doble grafía plena en Esth 2,14 que en $\mathrm{L}$ carece de masora ${ }^{15}$.

El texto y la MP de M1 es coherente: en el pasaje de Esth 2,14 el texto es doblemente pleno y carece de masora.

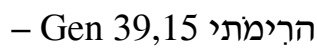

M1: $\quad$ ג (3 pasajes y sus sîmanîm están escritos)

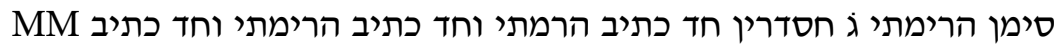
הרימותי וסימנהון... קדמאה חסיו חסיב דחסרין תנינה כסיב חסר וא בתראה שלם וחדיב דשלמין

BHS: $\quad$ MP $\dot{\lambda}(3$ pasajes)

Según la MM de M1 hay tres grafías defectivas: הרמתי (Gen 14,22) grafía defectiva de 1 y de ', cuya MP informa de que es caso único con grafía defectiva; הרימתי (Gen 39,15) grafía defectiva de ו, y הרימותי (P9,20) con grafía doblemente plena. Así lo especifica en el final de la información la MM de M1: la primera palabra, con grafía doblemente defectiva, la segunda, defectiva de waw, la tercera, con grafía doblemente plena.

${ }^{14}$ Con esta expresión indica Weil que «se ha efectuado una corrección en relación con la nota de L o que se origina una dificultad por el hecho de que en el manuscrito citado falta la lista correspondiente de Mm». Cf. WeIL, Prolegomena, pág. XXXIV.

${ }^{15}$ A. Dotan, אוצר המסורה הטברנית... המסורה לספר בראשית בכ"י לנינגרד (Tel-Aviv 1977) pág. 160, anota el pasaje y aporta el testimonio de R. Meîr ben Todros ha-Levî: «Caso único escrito así, pleno, en la Torah». Posibles explicaciones del proceder de Weil en D. S. Mynatt, The sub loco notes, pág. 66 , nota $\mathrm{n}^{\circ} 57$. 
Aquí hay que hilar muy fino para entender al masoreta, por dos motivos: en Gen 14,22 el texto de L es הרימתי, הרמתי de M1; la información podría equivocarnos, haciéndonos pensar que, según M1, hay tres casos de grafía defectiva, cuando lo que hay, en realidad en este manuscrito son tres grafías defectivas en dos palabras; de ahí que la MM aclare que el último caso tiene grafía doblemente plena. Es decir, la MM de M1 es coherente en los tres pasajes con el texto del manuscrito, aunque difiera de BHS. En esta edición encontramos en la MP de los dos pasajes de Génesis la anotación ג y en la de Salmos גל גל מל. Las grafías de M1 están confirmadas por Ginsburg II pág. 573 § 267.

Posibles discrepancias entre las fuentes

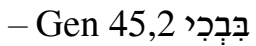

M1: $\quad$ MP ה רפיין (5 pasajes con rafeh)

BHS: MP i, y en nota, «Mp sub loco»

L: $\quad$ MP

Ginsburg I pág. $183 \S 307$ recoge seis pasajes: Gen 45,2; Is 16,9; 15,5; Ier 48,5; 31,9; Ps 102,10. M1 tiene la anotación i en la MP de Is 16,9, Ier 31,9 y Ps 102,10; en Ier 31,9 tiene además MM, cuyos sîmanîm coinciden con los pasajes consignados por la citada lista de Ginsburg.

El códice L anota i en MP de Is 16,9 y Ier 31,9; en Ps 102,10, simplemente $ל$. En BHS los cinco primeros casos, tengan o no MP, llevan la indicación i introducida por Weil, y en Ps 102,10, ול בספ con la anotación «Mp sub loco».

Éste es un caso claro de discrepancia entre las fuentes e incluso de inconsistencias en algunas. Ginsburg ${ }^{16}$ comenta sobre

Of this Rubric I collated seven Lists, six in MSS. and one printed... That there must have been some uncertainty about the reading of this quadriliteral in some MSS. is evident from Lists II and III which are in two carefully written Model Codices. Thus List II heads this Rubric בבכי ה' בקרי and enumerates four only, omitting Gen. 452 and Ps. 102 10, whilst List III which is headed and which also gives four instances only, omits Isa. 169 and Jerem.

48 5. List IV which, like List II, is headed ה' רפ' gives all the six.

${ }^{16}$ The Massorah, IV pág. 207 § 307. 
Para conciliar las noticias $\dot{n}$ y $i$, podría interpretarse que el in se refiere al número de veces en los que la palabra aparece en Pentateuco y Profetas. El ל de Salmos parece avalar esta teoría ${ }^{17}$.

- Gen 39,1 ויוֹסקס

M1: $\quad$ MP ג ראש פסi (3 veces a principio de versículo)

MM: ..... (7 pasajes, 3 de ellos a principio de versículo... y 2 que tienen el sentido de 'acrecentar')

BHS: יג מנה ר״יפ (10 pasajes, 3 de ellos a principio de versículo)

L:

La MP de M1 nos informa tan sólo de que la palabra tres ocasiones a principio de versículo. La MM completa la información: los casos [de nombre] son siete, tres de ellos a principio de versículo y además hay dos casos [que no son nombre, sino verbo, $3^{\mathrm{a}}$ persona del futuro hif $\hat{\imath} l \mathrm{l}$ de la raíz יסף] con el sentido de 'acrecentar'. En el orden de los sîmanîm aparecen los siete casos de nombre -los tres primeros, los que van a principio de versículo- (Gen 39,1; 41,46 y 42,6; Gen 44,4; Ex 1,5; Gen 46,4 y Ps 77,16) y al final los dos pasajes en los que se trata de un verbo (2 Sam 24,3 y Prov 1,5). Así llegamos al número nueve, que discrepa del diez que aparece tanto en Weil 1858 (la MM se encuentra en el pasaje de Samuel) como en Ginsburg I pág. 717 § 269.

El número diez que da Weil ${ }^{18}$ y que desarrolla en la lista 1858 no se corresponde con el que aparece en el manuscrito $L$ en el pasaje de Samuel, que es el de siete, aunque luego recoja diez sîmanîm sin especificación alguna de las diferencias: Gen 39,1; 41,46; 42,6; 46,4; 46,4; Ex 1,5; Deut 27,12; 1 Par 25,2; Ps 77,16 y 2 Sam 24,3 .

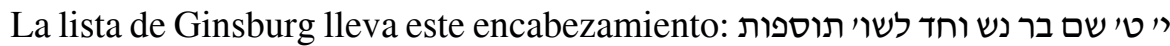
, es decir, los casos son diez, en nueve es nombre propio y hay un caso en Profetas con el sentido de 'acrecentar'. Los sîmanîm son los siguientes: Gen 39,$1 ; 41,46 ; 42,6 ; 44,4 ; 46,4$; Ex 1,5; Deut 27,12; 1 Par 25,2; Ps 77,16 y 2 Sam 24,3, exactamente igual a los del manuscrito $\mathrm{L}$.

\footnotetext{
${ }^{17}$ Cf. Dotan, אוצר, s.v. בכי בְּבְכִ pág. 49 y Mynatt, The sub loco, nota 94, págs. 93-94.

18 *. WeIL, Massorah Gedolah, pág. XXIII: «l'asterisque placé après un mot signale un mot erroné qui a été corrigé».
} 
Si recurrimos a las Concordancias de Mandelkern ${ }^{19}$ encontramos ocho casos de nombre propio; en cuanto a los relativos al verbo יסף, distingue entre los

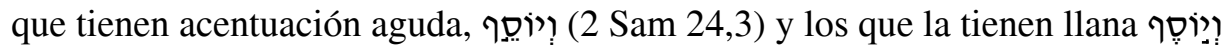
(Prov 1,5; 9,9).

En resumen: en la MM de M1 falta uno de los pasajes del nombre propio, Deut 27,12 , y se ha incluido un caso de verbo que no va acentuado con șerê sino con segôl. La información del manuscrito L es correcta, pero demasiado escueta, porque no especifica los casos que van a principio de versículo ni los dos campos semánticos que afectan a la palabra. En las Concordancias de Mandelkern falta uno de los pasajes de nombre propio, 1 Par 25,2.

La información correcta y completa es la dada por Ginsburg, que queda totalmente explicada y aclarada en el vol. IV de su Massorah, con indicación de las fuentes que utilizó, sus distintos encabezamientos y sus diferentes contenidos ${ }^{20}$.

Puede pensarse, sin embargo, que alguno de los errores de los masoretas provinieran, precisamente, de su conocimiento del texto, de asociaciones inconscientes de ideas.

En Gen 31,32, respecto a la palabra מָה, las masoras de M1 informan de que se vocaliza con qameș cuando la palabra siguiente comienza por las letras $n \mathrm{y}$ $\nu$, salvo en dos ocasiones en las que se vocaliza con patah. Entre los pasajes vocalizados con qameș figura 2 Reg 8,13, con el siguiente sîman: כי מה עבדך הכלב המת, que traducido literalmente es: «¿Pues qué es tu servidor, este perro muerto?» ${ }^{21}$. La palabra 'muerto' no aparece en el pasaje. Entonces, ¿por qué había fallecido tal perro? En el Antiguo Testamento hebreo aparecen un perro vivo (Eccle 9,4) y tres perros muertos (1 Sam 24,15; 2 Sam 9,8; 16,9). La lectura de estos tres últimos pasajes determina el diagnóstico: el perro de Reyes murió por contaminación del perro de 2 Sam 9,8: «QQué es tu servidor para que te hayas vuelto hacia un perro muerto como yo?».

No hay que olvidar que las informaciones masoréticas nunca fueron sistematizadas. En las listas existentes, las compilaciones, las incorporadas a distintos manuscritos, hay diferencias. Esas diferencias tienen un gran valor, no sólo para la historia de la Masora misma sino también para la de los textos a los que acompañan.

${ }^{19}$ S. Mandelkern, Veteris Testamenti Concordantiae Hebraicae atque Chaldaicae, 2 vols. (Graz 1896). Editio altera locupletissime aucta et emendata cura F. MARGOLIN (Graz 1955), vol. II, pág. 1438 para el nombre propio; vol. I, pág. 487 para el verbo ףסי.

${ }^{20}$ Ginsburg, The Massorah, IV pág. $485 \S 269$.

${ }^{21}$ La cursiva es mía. 
Ya hemos visto un ejemplo de esas dificultades en los testimonios de Ginsburg respecto a בִבְבְִ en Gen 45,2. Un ejemplo más:

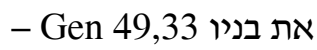

M1: $\quad$ MP ד וכל נביא וכתובי כותחון בר מן (cuatro pasajes, y en todos los casos de Profetas y Escritos se escribe igual, salvo en 6 ocasiones)

BHS: דיר

Al buscar la confirmación o el desarrollo de esta noticia, encontramos en Ginsburg I pág. 122 § 1252: ד וכל נביא' וכתובי' דכות' במ"ד [ואת בניו] (cuatro pasajes, y en todos los casos de Profetas y Escritos se escribe igual, salvo en 4

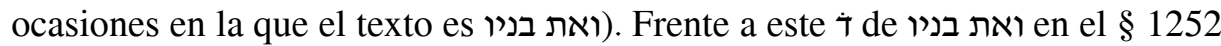
(Ios 7,24; 1 Sam 16,5; 30,22 y 31,2) encontramos en el § 1327 la enumeración de seis pasajes, los cuatro anteriores más 1 Par 10,8 y Esth 9,25. Ginsburg IV pág. $144 \S 1252$ explica las diferencias entre las listas y ediciones consultadas; incluso en un mismo manuscrito aparecen dos recensiones diferentes de la misma lista.

Habrá que concluir, pues, que en algunas ocasiones el masoreta, sí, se equivocaba.

Sin embargo...

Recibido: 07/05/2008

Aceptado: 30/04/2009 